\title{
Study on the Mechanism of Exchange Rate Communication and Actual Intervention on the Exchange Rate Pricing of RMB
}

\author{
Hong Guo, Hua Li \\ Economics School, Tianjin University of Finance and Economics, Tianjin, 300222, China
}

Keywords: Exchange rate communication, Actual intervention, Effectiveness of foreign exchange intervention.

\begin{abstract}
Exchange rate communication and practical intervention are the two policy instruments of foreign exchange intervention. As the central bank of our country is out of the normal mode of foreign exchange market intervention, exchange rate communication will play a more important role in the exchange rate adjustment. Based on the SVAR model, this paper evaluated the effectiveness of exchange rate communication, and compared it with the actual intervention. The results showed that the exchange rate communication could change the direction of the exchange rate to the monetary authorities in a short time, and it would be effective in a long period, so it was an effective exchange rate policy tool.
\end{abstract}

\section{Introduction}

Exchange rate communication and actual intervention are the two main ways of foreign exchange intervention in the central bank. The so-called exchange rate communication, is also known as verbal intervention, is a way of foreign exchange intervention, refers the monetary authorities to declare in public their standpoint and tendency of the exchange rate, pass their exchange rate policy information to the market participants, thus affect the exchange rate changes. This way of intervention continuously strengthen the communication of monetary authorities and market participants to guide the public to form a reasonable exchange rate expectations, so as to achieve the goal of exchange rate policy.

In recent years, with the deepening reform of the RMB exchange rate system, the foreign exchange market is becoming more and more perfect, and the level of formation mechanism of the RMB exchange rate market continues to be improved. The central bank of China has basically quit normal foreign exchange market intervention, that is, by buying or selling foreign exchange in the foreign exchange market to affect the exchange rate. That means the exchange rate communication as a policy instrument to adjust the exchange rate will play a greater role.

\section{Theoretical analysis and model construction}

In the theory of foreign exchange intervention, actual intervention is the most important policy tool, this is because, on the one hand the direction, time and scale of the actual intervention is fully controlled by the central bank, so that the central bank can take the initiative to intervene the implementation of the policy accurately. On the other hand, the actual intervention directly changes the relative supply and demand of RMB and foreign currency in the foreign exchange market, which can have a direct impact on the exchange rate, thereby the goal of foreign exchange intervention can be achieved. But in the interest rate parity theory of exchange rate determination, exchange rate expectation is also an important factor to decide and affect the exchange rate:

$$
i_{d}-i_{f}=\frac{e^{e}-e}{e}
$$

In the equation, $i_{d}$ and $i_{f}$ stand for the domestic and foreign interest rates respectively, $e$ stands for the current exchange rate, $e^{e}$ stands for the expectations of future exchange rate. When the market participants expect that the domestic currency will depreciate in the future, on the condition of the 
unchanged interest rate of the two countries, the market participants will throw out the domestic currency, and buy foreign currency, which will lead to devaluation of the domestic currency. Therefore, guiding market participants to form a reasonable exchange rate expectation can effectively adjust the exchange rate changes, so as to achieve the policy goals of foreign exchange intervention

However, in reality, there is serious information asymmetry between market participants and the central bank, the specific performances are: market participants do not understand the central bank's acceptable exchange rate target level; market participants do not understand the economic prospects of the future; market participants do not understand the operation direction and scale of actual intervention of central bank and so on. The asymmetry of information seriously affected the formation of reasonable exchange rate expectations of the market participants, while the central bank's effective exchange rate communication can greatly reduce the information asymmetry, compared with the actual, it has the advantages of guiding public expectations. So exchange rate communication has become an important policy tool the central bank manages the market participants' exchange rate expectations, and then adjusts the exchange rate.

Although, the central bank's exchange rate communication has the theoretical rationality as a foreign exchange intervention tool, but if it can be supported by empirical evidence, we need to learn from the relevant research ideas, to test the feasibility of exchange rate communication as a policy tool.

A model was constructed according to the factors that affect the exchange rate, we introduce variables like exchange rate communication, actual intervention, foreign trade situation, the real interest difference between two countries and the short-term cross-border capital flow, etc., the model is built as follows:

$$
\Delta s=\alpha_{0}+\alpha_{1} I O+\alpha_{2} I A+\alpha_{3} C F+\alpha_{4} F T+\alpha_{5} \Delta i
$$

In the equation, $\Delta s$ stands for change in exchange rate; $I O$ and $I A$ stand for exchange rate communication and actual intervention; CF stands for cross-border capital flow; FT stands for trade situation; $\Delta i$ stands for the interest difference between two countries.

\section{Model analysis}

Data selection. Since July 2005, China carried out the reform of the RMB exchange rate regime, it was pegged to the dollar before, the RMB exchange rate was in stable condition, so this paper selected the monthly data from July 2005 to December 2014 to carry out the measurement analysis.

Exchange rate communication (IO)

Compared to other variables, exchange rate communication is the most difficult to measure. Since the effect on exchange rate of exchange rate communication is through declaring their standpoint and tendency of the exchange rate, pass their exchange rate policy information to the market participants, to guide the market exchange rate expectations to achieve the effect of the exchange rate, so exchange rate data must have the following characteristics: firstly, the statement on the exchange rate central bank issued must be through the public media that can be informed by market participants; secondly, it must be the direct release of monetary policy and exchange rate policy makers. In this paper, the exchange rate communication data was attained by the search engine Baidu, the relevant statements of the governor of our country's central bank on the exchange rate are as basic data. The quantitative approach is to give the statement of the central bank governor on the effect of direction of exchange rate changes the virtual variable value, when the exchange rate communication has a tendency of domestic currency appreciation, the assignment is +1 ; neutral statements or statements of the current exchange rate moderate, the assignment is 0 ; when the communication has a tendency of devaluation, the assignment is -1 . If there are many statements in one month, we accumulate the monthly communication signal value. Defined as:

$$
I O_{T}=\sum n_{t} / N_{T}
$$


In the equation, $n_{t}$ stands for the Assignment of communication at t time, $N_{T}$ stands for the times of the communication in $\mathrm{T}, I O_{T}$ is the signal value of the communication in $\mathrm{T}$.

Actual intervention(IA)

This paper chooses the change of foreign exchange reserves as the substitute variable of the actual intervention by referring to the previous literatures and based on the availability of data. The data comes from the official website of the foreign exchange administration.

Short term cross-border capital flow(CF)

In this paper, we choose the modified indirect method to calculate the short term cross-border capital flow, the formula is: short term cross-border capital flow= incremental foreign exchangefrequent item surplus- Increase in the amount of direct investment by foreign businessman- net inflow of foreign debt+ errors and omissions. The increase in the amount of direct investment by foreign businessman can be showed by the actual use of foreign investment in monthly data and can be obtained from the website of national Ministry of Commerce. The increase in the amount of external debt can be obtained by the first order difference of the balance of the external debt in quarterly data smoothes monthly data, can be get from the macro monthly library of China Economic Net.

Foreign trade status(FT)

Take our country's import and export balance as an alternative variable, the data can be get from the website of National Bureau of Statistics.

The actual interest margin of China and America( $\Delta i)$

The actual interest margin between the two countries by the two countries' real interest rates= nominal interest rate-inflation rate. The nominal interest rate in our country is the weighted average of the interest rate of the national interbank lending market in 30 days, monthly inflation data is get from the National Bureau of Statistics website. The nominal interest rate in the United States is replaced by the monthly effective federal rate, which is published on the Federal Reserve's website, and inflation rate is measured by the US CPI change rate, which can be obtained from the U.S. Department of labor's website.

The fluctuation of $R M B$ exchange rate $(\Delta S)$

The changes of the RMB exchange rate is the average value of the central parity of RMB spot rate every month obtained from the website of the National Foreign Exchange Management Bureau, take the $\Delta \mathrm{S}$ as its monthly rate change (expressed by direct price method).

$$
\Delta s=\frac{\overline{e r_{t}}-\overline{e r_{t-1}}}{\overline{e r_{t-1}}} \times 100 \%
$$

$\overline{e r}$ stands for the average value of the spot rate in the same month by the direct price method, $\overline{e r_{t-1}}$ stands for the average value of the spot rate of the previous month by the direct price method.

Setting and analysis of SVAR model. In this paper, we adopt the exchange rate communication (IO), actual intervention (IA), short-term cross-border capital flow (CF), the balance of income and expenses of trade (FT), the actual interest margin of China and America ( $\Delta i$ ), and the change rate of RMB spot exchange rate $(\Delta S)$ to construct the SVAR model to analyze the effect of exchange rate communication and the actual intervention on the RMB exchange rate changes.

Unit root test

ADF unit root test is used to test the stability of variable sequence. Null hypothesis is that unit root is existence. As is shown in Table 1, in addition to the actual interest margin of China and America $(\Delta i$ ) is not stable, other variables below $5 \%$ significantly rejected the null hypothesis, and are stationary time series. Since after order difference of the non stationary variables, and then incorporate it into the SVAR model, the interactive information in the data will be lost, and only one variable is not stable, so the level values of all the variables is directly incorporated into the SVAR system in this article. 
Table1. Variable unit root ADF test

\begin{tabular}{|c|c|c|c|}
\hline variables & testing form & $\mathrm{P}$ value & Testing results \\
\hline $\mathrm{IO}$ & $(\mathrm{C}, \mathrm{T}, 0)$ & 0.0000 & stable \\
\hline IA & $(\mathrm{C}, \mathrm{T}, 0)$ & 0.0000 & stable \\
\hline $\mathrm{CF}$ & $(0,0,1)$ & 0.0001 & stable \\
\hline FT & $(\mathrm{C}, \mathrm{T}, 0)$ & 0.0000 & stable \\
\hline$\Delta S$ & $(\mathrm{C}, 0,1)$ & 0.0193 & stable \\
\hline$\Delta \mathrm{i}$ & $(\mathrm{C}, \mathrm{T}, 0)$ & 0.2319 & non-stable \\
\hline $\mathrm{D}(\Delta \mathrm{i})$ & $(0,0,0)$ & 0.0000 & stable \\
\hline
\end{tabular}

\section{SVAR model setting}

In the setting of the SVAR model, we first have to determine the appropriate lag order. As is shown in Table 2, the appropriate lag order based on various criteria is 1. So we adopt SVAR model of Stage 1 .

$$
\mathrm{BX}_{\mathrm{t}}=\prod_{0}+\prod_{1} \mathrm{X}_{\mathrm{t}-1}+\varepsilon_{\mathrm{t}}
$$

$\mathrm{B}$ is a reversible matrix, $\varepsilon_{\mathrm{t}}$ is white noise interference term, which is a structural shock vector, $\operatorname{Var}\left(\varepsilon_{t}\right)=\mathrm{I}$, I is $(6 \times 6)$ dimension of the unit matrix

Table 2. Lag order selection

\begin{tabular}{ccccccc}
\hline Lag & LogL & LR & FPE & AIC & SC & HQ \\
\hline 0 & -511.9574 & NA & 0.014434 & 12.78907 & 12.96644 & 12.86023 \\
\hline 1 & -397.2573 & 209.5755 & $0.002073^{*}$ & $10.84586^{*}$ & $12.08743^{*}$ & $11.34399^{*}$ \\
\hline
\end{tabular}

\section{Cointegration test}

As the lag order is 1 , the Johansen cointegration test of the variables is carried out, and the results of cointegration test show in Table3 that there is a long-term stable equilibrium relationship among the variables.

Table 3. Rresults of cointegration test

\section{Granger causality test}

\begin{tabular}{ccccc}
\hline No. of CE(s) & Eigenvalue & Statistic & Critical Value & Prob.** \\
\hline None * & 0.591566 & 268.7306 & 95.75366 & 0.0000 \\
\hline At most $1 *$ & 0.513052 & 189.9332 & 69.81889 & 0.0000 \\
\hline At most 2 & 0.454054 & 126.6086 & 47.85613 & 0.0000 \\
\hline At most 3 * & 0.340341 & 73.34787 & 29.79707 & 0.0000 \\
\hline At most 4 & 0.319955 & 36.73709 & 15.49471 & 0.0000 \\
\hline At most 5 & 0.031368 & 2.804628 & 3.841466 & 0.0940 \\
\hline
\end{tabular}

From the results of Granger causality test, we can see that there is a one-way causal relationship between the interest margin of China and America and the actual intervention, short-term capital flow, the balance of income and expenses of trade and the change rate of RMB exchange rate at a significant level of 5\%. Short term capital flow is the Granger reason of the balance of income and expenses of trade, and the balance of income and expenses of trade is the Granger reason of the exchange rate communication.

Impulse response and variance decomposition

According to the results of Granger causality test, the order of impact of the variables is $\Delta \mathrm{i} \rightarrow \mathrm{IA}$ $\rightarrow \mathrm{CF} \rightarrow \mathrm{FT} \rightarrow \mathrm{IO} \rightarrow \Delta \mathrm{S}$. Figure 1 shows the impulse response function of the RMB exchange rate fluctuation in 12 periods after the impact of a positive actual intervention. The results showed that the actual intervention in the first two periods made the exchange rate negative, then gradually stable. That is, the central bank buy foreign exchange in the market, will make the RMB appreciation, and then make the RMB exchange rate stable. According to the basic principle of exchange rate theory, the central bank buy foreign exchange, hold foreign exchange reserves, the RMB should depreciate, but in the context of our country's continued double surplus and the current foreign exchange management regime, the central bank become the largest bank in the interbank foreign exchange 
market. This passive increase of the foreign exchange reserves make the central bank's intervention intent difficult to reflect immediately.

Response to Cholesky One S.D. Innovations \pm 2 S.E.

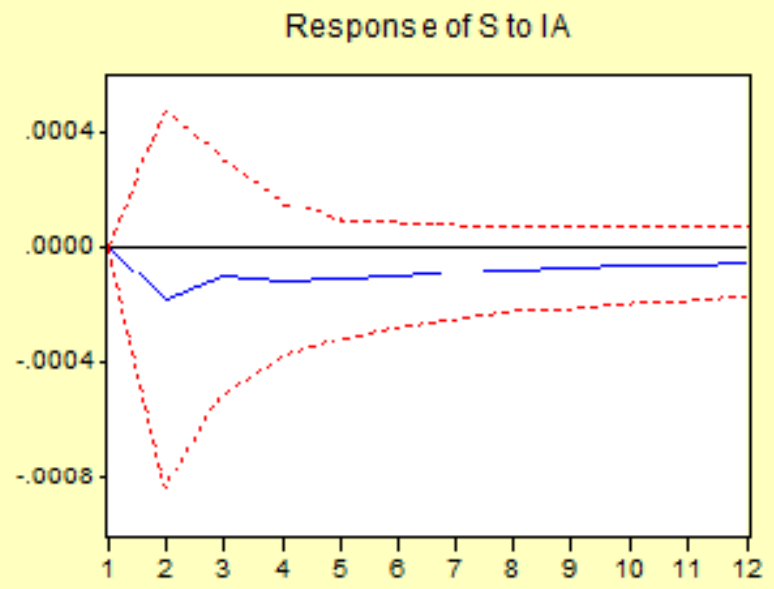

Fig. 1. Impulse response of exchange rate fluctuation to actual intervention

Figure 2 shows the impulse response function of the RMB exchange rate fluctuation in 12 periods after the impact of a positive exchange rate communication. As is shown in the picture, when a positive standard exchange rate communication was given, the effect of the exchange rate changes in the first 5 periods was negative, that was, if the exchange rate policy makers taking the statement on strengthening their currencies would lead to a decline in exchange rate and their currency appreciation. In the second period, the RMB appreciation range reached the maximum value, after that, the RMB appreciation range gradually decreased, and a tendency slight depreciation of RMB in sixth period, the impact slowly disappeared until the tenth period. This shows that, exchange rate communication can pass the exchange rate policy signal of central bank to the market participants through the expected channels, impacts the market participants' exchange rate expectations, thereby affecting the market participants' foreign trading behavior in the market exchange. Exchange rate communication can make the direction of exchange rate change as the monetary authorities' thoughts, and lasts for a period of time.

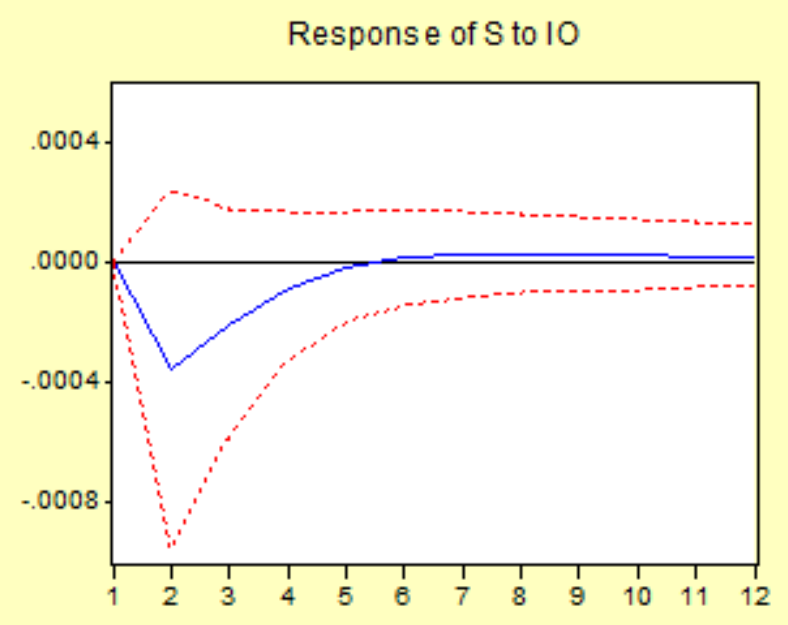

Fig. 2. Impulse response of exchange rate change to exchange rate communication

By the variance decomposition, we can further understand the importance of the impact of various variables in explaining exchange rate changes. As is shown in table 4, the impact of exchange rate changes, trade balance, the interest margin of the two countries as well as the actual intervention will gradually increase with time going. The interpretation of the effect of two countries exchange on rate 
changes is the strongest, the trade balance and the actual intervention is weaker. The explanatory power of short-term capital flow is the strongest in the third period, and then decreases with the time going. Compared to actual intervention, the verbal intervention has the most explanatory power, its power is strongest in the fourth period.

Table 4. Variance decomposition of exchange rate changes

\begin{tabular}{ccccccc}
\hline period & CF & FT & $\Delta \mathrm{i}$ & IA & IO & $\Delta \mathrm{S}$ \\
\hline 1 & 0.000000 & 0.000000 & 0.111288 & 0.000000 & 0.000000 & 99.88871 \\
2 & 2.399897 & 0.005819 & 2.286063 & 0.318136 & 1.220935 & 93.76915 \\
3 & 2.499168 & 0.120573 & 5.122436 & 0.402485 & 1.533101 & 90.32224 \\
4 & 2.402988 & 0.266786 & 7.880327 & 0.505889 & 1.531859 & 87.41215 \\
5 & 2.334375 & 0.361277 & 10.33044 & 0.600698 & 1.485409 & 84.88780 \\
6 & 2.280352 & 0.417878 & 12.43160 & 0.668569 & 1.447579 & 82.75402 \\
7 & 2.234272 & 0.455260 & 14.20499 & 0.714613 & 1.419750 & 80.97111 \\
8 & 2.194918 & 0.483030 & 15.69348 & 0.747439 & 1.398018 & 79.48312 \\
9 & 2.161557 & 0.505314 & 16.94309 & 0.772598 & 1.380171 & 78.23727 \\
10 & 2.133350 & 0.523868 & 17.99516 & 0.792954 & 1.365183 & 77.18949 \\
11 & 2.109479 & 0.539545 & 18.88414 & 0.809925 & 1.352492 & 76.30442 \\
12 & 2.089228 & 0.552866 & 19.63802 & 0.824276 & 1.341708 & 75.55391 \\
1 & 0.000000 & 0.000000 & 0.111288 & 0.000000 & 0.000000 & 99.88871 \\
\hline
\end{tabular}

\section{Conclusions and policy recommendations}

In this paper, we evaluate the effect of exchange rate communication on exchange rate fluctuation, and compare it with the effect of the exchange rate policy of actual intervention, we find that it's an effective exchange rate policy tool. Exchange rate communication policy hardly lags, and can make the exchange rate develop in the direction of monetary authorities in a relatively short period of time, and be effective in a longer period of time. But in the analysis of variance decomposition, the absolute value of the explanatory power of exchange rate communication is lower, so the exchange rate communication is still to be improved

To improve the effect of the exchange rate communication on the RMB exchange rate changes, the exchange rate communication mechanism of our country need to be improved. On the one hand, we must construct the system environment of the effective communication of the central bank. Exchange rate communication should be added with appropriate actual intervention, for fear that market participants believe the central bank's exchange rate communication "untrustworthy", and pay no attention to the communication. To ensure the independence of the central bank can avoid the market participants not determining which department to follow when there is inconsistent information between the central bank and other relevant departments, which will lost the effectiveness of communication.

On the other hand, the clarity, accuracy and intelligibility of communication information need to be improved. The effectiveness of the exchange rate communication depends on the expected channels to play a role, whether exchange rate communication information can effectively guide the public's expectations to develop in accordance with the wishes of the central bank, in a large extent depends on whether exchange rate communication information is clear, accurate and easy to understand. So the central bank should try to reduce the ambiguity of the speech to avoid the media to continue speculating on these issues, so that the market expectations will appear confused. For high accuracy communication, the central bank should emphasize the condition of the information; for low accuracy information, the central bank should be cautious and widely disclosure related information to facilitate the economic main bodies to make the right decisions. In addition, the central bank should adopt a variety of effective communication methods for different objects to understand the exchange 
rate, the content should be easy to understand to make the public understand the central bank's communication mechanism. At the same time in-depth communication should be carried out with the media and related experts and scholars to play their role in the dissemination of information filtering.

\section{Acknowledgments}

This paper is financed by the philosophy and social science planning project "Foreign exchange intervention research on the RMB exchange rate dynamic conversion" of Tianjin,NO.:TJYY12-025; and the pre-research project "Study on the mechanism of foreign exchange intervention in the process of exchange rate converting" exchange rate changing of Tianjin University of Finance and Economics ,NO.:Y1202.

\section{References}

[1] Beine, Janssen, \& Lecourt, Should Central Bankers Talk to the Foreign Exchange Markets. Journal of International Money and Finance, 2009(28):776-803.

[2] Fatum, Hutchison, ECB Foreign Exchange Intervention and the Euro: Institutional Frameworks, News, and Intervention. Open Economics Review, 2002,13(4):413-425.

[3] Fratzscher, Marcel, Oral Interventions versus Actual Interventions in FX Markets: An Event Study Approach. The Economic Journal, 2008,118(530):1079-1106.

[4] Xindi Gan, Jinmei Yang, Jun Zhang. The time analysis of the effectiveness of the central bank foreign exchange intervention in our country. Financial research. 2007(9)

[5]Yunfeng Li, Intervention in the foreign exchange market: Exchange rate communication and actual intervention. Shanghai Finance. 2011(4)

[6]Yunfeng Li, Exchange rate communication, actual intervention and exchange rate fluctuations. International Finance Research, 2011(4) 